\title{
Hybrid Multilevel Power Conversion System: A Competitive Solution for High-Power Applications
}

Madhav D. Manjrekar, Student Member, IEEE, Peter K. Steimer, Member, IEEE, and Thomas A. Lipo, Fellow, IEEE

\begin{abstract}
Use of multilevel inverters has become popular in recent years for high-power applications. Various topologies and modulation strategies have been investigated for utility and drive applications in the literature. Trends in power semiconductor technology indicate a tradeoff in the selection of power devices in terms of switching frequency and voltage-sustaining capability. New power converter topologies permit modular realization of multilevel inverters using a hybrid approach involving integrated gate commutated thyristors (IGCT's) and insulated gate bipolar transistors (IGBT's) operating in synergism. This paper is devoted to the investigation of a hybrid multilevel power conversion system typically suitable for high-performance high-power applications. This system, designed for a 4.16-kV $>100-\mathrm{hp}$ load is comprised of a hybrid seven-level inverter, a diode bridge rectifier, and an IGBT rectifier per phase. The IGBT rectifier is used on the utility side as a real power flow regulator to the low-voltage converter and as a harmonic compensator for the high-voltage converter. The hybrid seven-level inverter on the load side consists of a high-voltage slow-switching IGCT inverter and a low-voltage fast-switching IGBT inverter. By employing different devices under different operating conditions, it is shown that one can optimize the power conversion capability of the entire system. A detailed analysis of a novel hybrid modulation technique for the inverter, which incorporates stepped synthesis in conjunction with variable pulsewidth of the consecutive steps is included. In addition, performance of a multilevel current-regulated delta modulator as applied to the single-phase full-bridge IGBT rectifier is discussed. Detailed computer simulations accompanied with experimental verification are presented in the paper.
\end{abstract}

Index Terms-Converters, inverters, multilevel topologies.

\section{INTRODUCTION}

$\mathbf{M}$ ULTILEVEL power conversion has been receiving increasing attention in the past few years for high-power applications [1]. Numerous topologies and modulation strategies have been introduced and studied extensively for utility and drive applications in the recent literature [2]. These converters are suitable in high-voltage and high-power applications due to their ability to synthesize waveforms with better harmonic

Paper IPCSD 99-84, presented at the 1999 Industry Applications Society Annual Meeting, Phoenix, AZ, October 3-7, and approved for publication in the IEEE TRANSACTIONS ON INDUSTRY APPLICATIONS by the Industrial Power Converter Committee of the IEEE Industry Applications Society. Manuscript submitted for review June 1, 1999 and released for publication December 9, 1999.

M. D. Manjrekar and T. A. Lipo are with the Department of Electrical and Computer Engineering, University of Wisconsin, Madison, WI 53706 USA (e-mail: manjreka@cae.wisc.edu; lipo@engr.wisc.edu).

P. K. Steimer is with ABB Industrie AG, 5300 Turgi, Switzerland (e-mail: peter.steimer@ch.abb.com).

Publisher Item Identifier S 0093-9994(00)03170-4. spectrum and attain higher voltages with a limited maximum device rating. In the family of multilevel inverters, topologies based on series-connected $\mathrm{H}$-bridges are particularly attractive because of their modularity and simplicity of control [3]. Such H-bridge multilevel inverters have also been implemented successfully in the industrial applications for high-power drives [4]. A typical seven-level configuration reported in the literature is shown in Fig. 1. As may be seen from this figure, this conventional seven-level inverter is comprised of three $\mathrm{H}$-bridge cells (referred to as "power cells") per phase. All power cells have independent dc links of equal magnitude $(\mathrm{V})$. The input transformer provides isolation to individual cells and is configured so as to obtain an 18-pulse current waveform at the utility side. This particular system is designed for $2.3-\mathrm{kV}$ drive applications, and an extended 11-level version is also reported for $4.16-\mathrm{kV}$ applications [4].

Recent trends in the power semiconductor technology indicate a tradeoff in the selection of power devices in terms of switching frequency and voltage-sustaining capability [5]. Normally, the voltage-blocking capability of faster devices such as insulated gate bipolar transistors (IGBT's) and the switching speed of high-voltage thyristor-based devices like integrated gate commutated thyristors (IGCT's) [6] is found to be limited. With a modular H-bridge topology, realization of multilevel inverters using a hybrid approach involving IGCT's and IGBT's operating in synergism is possible [7].

This paper is devoted to the investigation of a hybrid multilevel power conversion (HMPC) system for medium-voltage $(4.16 \mathrm{kV})$ high-power $(\geq 100 \mathrm{hp})$ applications. A simplified schematic of the power circuit of the proposed system is shown in Fig. 2. As may be observed, this system consists of one "hybrid cell" per phase. The hybrid cell is comprised of a seven-level hybrid inverter [8] with dc-bus voltages configured in the ratio $2: 1(2 \mathrm{~V}$ and $\mathrm{V})$ and a combination of a passive diode bridge and an active IGBT rectifier front end.

Section II of this paper presents a brief description of the hybrid multilevel inverter. Simulation and experimental results demonstrating the feasibility of this inverter are provided in Section III. Section IV describes the spectral analysis of the hybrid modulation scheme and issues of power interaction in the hybrid approach. The operating principles of the hybrid rectifier and description of the control strategy is presented in Section V. Section VI presents simulation results confirming the efficacy of hybrid rectification. The paper concludes in Section VII with a relative comparison of the proposed hybrid approach versus conventional methods adopted by the power industry. 

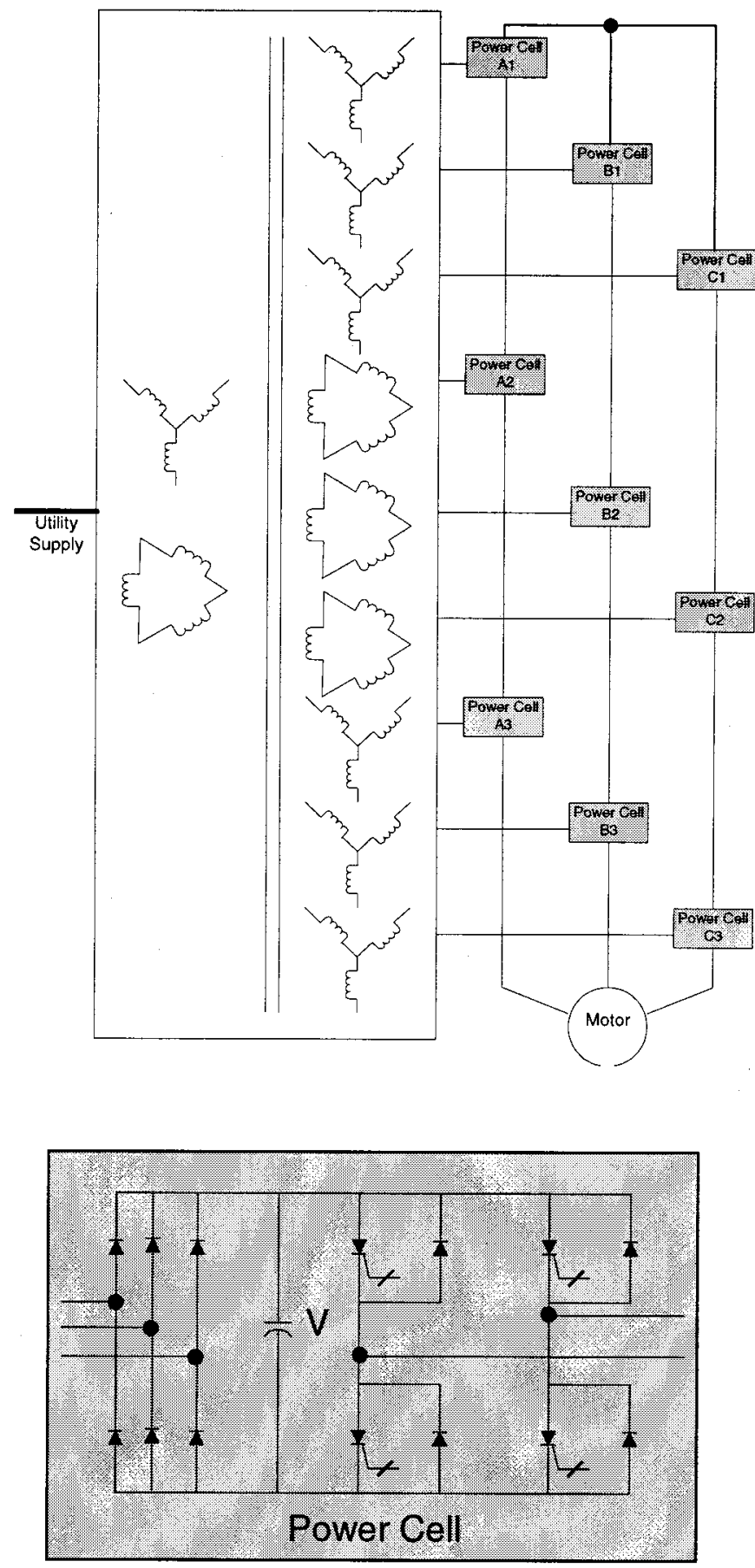

Fig. 1. Simplified schematic of the conventional [4] seven-level power conversion system for $2300-\mathrm{V}$ drive.

\section{PRINCIPLE OF THE HybRID Multilevel INVERTER}

The hybrid multilevel inverter combines an IGCT inverter with a $2.2-\mathrm{kV}$ bus and an IGBT inverter with a $1.1-\mathrm{kV}$ bus, as shown in Fig. 3. It may be easily verified that it is possible to synthesize stepped waveforms with seven voltage levels, viz., $-3.3,-2.2,-1.1,0,1.1,2.2,3.3 \mathrm{kV}$ at the phase leg output with this topology. As shown in Fig. 3, the higher voltage levels $( \pm 2.2 \mathrm{kV})$ are synthesized using an IGCT inverter while the lower voltage levels $( \pm 1.1 \mathrm{kV})$ are synthesized using IGBT in-
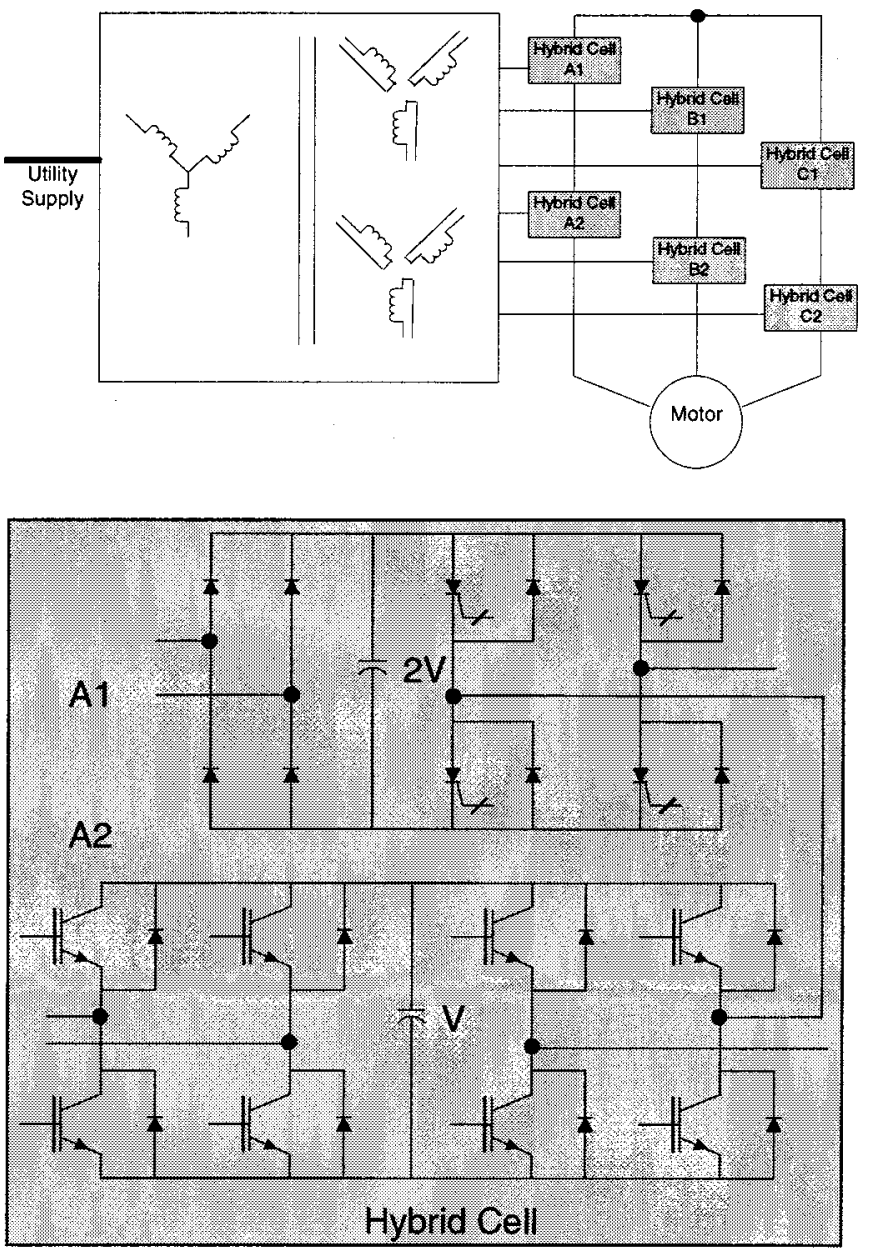

Fig. 2. Simplified schematic of the proposed hybrid seven-level power conversion system for $4160-\mathrm{V}$ drive.

verters. However, it is well known that the switching capability of thyristor-based devices is limited at higher frequencies [5]. Hence, a hybrid modulation strategy which incorporates stepped synthesis in conjunction with variable pulsewidth of consecutive steps has been presented in [8]. Under this modulation strategy, the IGCT inverter is modulated to switch only at fundamental frequency of the inverter output, while the IGBT inverter is used to switch at a higher frequency. The modulation process and the state of the inverters for various levels of command signals are summarized in Table I.

\section{SimUlation RESUltS AND EXPERIMENTAL VERIFICATION OF THE HYBRID MULTILEVEL INVERTER}

The hybrid multilevel inverter is controlled under hybrid modulation which combines a quasi-square-wave synthesis of the IGCT inverter with IGBT pulsewidth modulation (PWM), as shown in simulation results in Fig. 4. The circuit simulations are done in Saber. With this hybrid topology and modulation strategy, the effective spectral response of the output depends on the IGBT switching, while the overall voltage generation is decided by the voltage ratings of the IGCT's. This is demonstrated in the phase-leg voltage waveform in Fig. 5. This output 


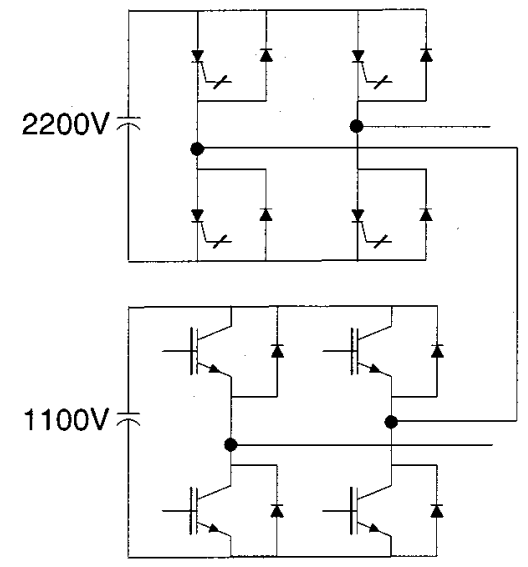

Fig. 3. Simplified schematic of one leg of the hybrid multilevel inverter.

TABLE I

HyBRID MODULATION SCHEME $a \leftrightarrow b$ : SWITCHING BETWEEN $a$ AND $b$

\begin{tabular}{c|c|c}
\hline Desired output between & IGCT Inverter & IGBT Inverter \\
\hline-3.3 and $-2.2 \mathrm{kV}$ & $-2.2 \mathrm{kV}$ & $0 \leftrightarrow-1.1 \mathrm{kV}$ \\
\hline-2.2 and $-1.1 \mathrm{kV}$ & $-2.2 \mathrm{kV}$ & $0 \leftrightarrow 1.1 \mathrm{kV}$ \\
\hline-1.1 and $0.0 \mathrm{kV}$ & $0 \mathrm{kV}$ & $0 \leftrightarrow-1.1 \mathrm{kV}$ \\
\hline 0.0 and $1.1 \mathrm{kV}$ & $0 \mathrm{kV}$ & $0 \leftrightarrow 1.1 \mathrm{kV}$ \\
\hline 1.1 and $2.2 \mathrm{kV}$ & $2.2 \mathrm{kV}$ & $0 \leftrightarrow-1.1 \mathrm{kV}$ \\
\hline 1.1 and $3.3 \mathrm{kV}$ & $2.2 \mathrm{kV}$ & $0 \leftrightarrow 1.1 \mathrm{kV}$ \\
\hline \multicolumn{3}{|c|}{$\mathrm{a} \leftrightarrow \mathrm{b}:$ Switching between $\mathrm{a}$ and $\mathrm{b}$}
\end{tabular}

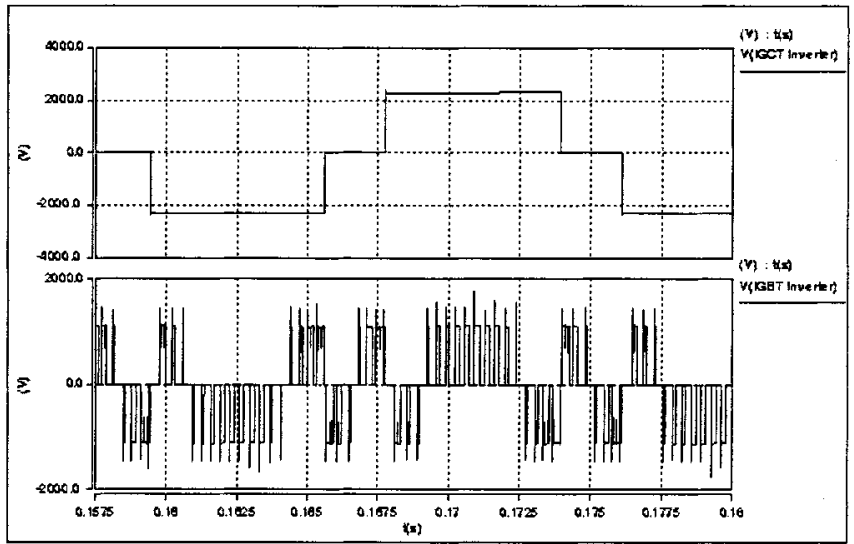

Fig. 4. Simulated IGCT and IGBT inverter waveforms, $M=0.83$ p.u. and $f_{c}=1440 \mathrm{~Hz}$.

is obtained from a command signal with modulation depth $(M)=0.83$ p.u. and switching frequency $\left(f_{c}\right)=1440 \mathrm{~Hz}$. A single leg of the hybrid multilevel inverter as shown in Fig. 3 is built in the laboratory and tested extensively. Representative waveforms at the same operating point confirming the validity of hybridization are shown in Figs. 6 and 7. Fig. 6 shows the IGCT and IGBT inverter output voltage waveforms obtained experimentally. Fig. 7 illustrates the phase-leg voltage waveform, load current, and the dc-bus voltages.

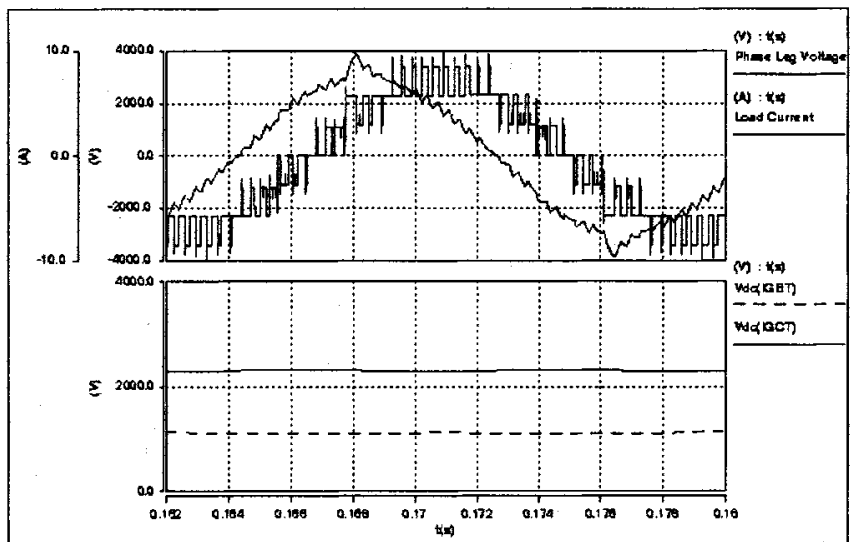

Fig. 5. Simulated load and dc-bus voltage waveforms, $M=0.83$ p.u. and $f_{c}=1440 \mathrm{~Hz}$.

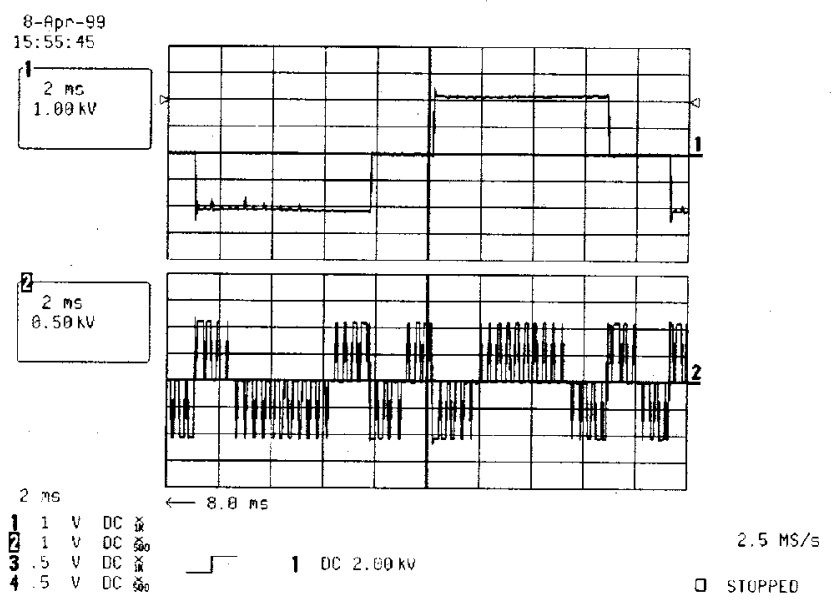

Fig. 6. Experimental IGCT and IGBT inverter waveforms, $M=0.83$ p.u. and $f_{c}=1440 \mathrm{~Hz}$. Trace 1: IGCT inverter voltage $1000 \mathrm{~V} /$ div. Trace 2: IGBT inverter voltage $500 \mathrm{~V} /$ div.

\section{SPeCtral ANALYSis AND POWER INTERACTION IN THE HYBRID MULTILEVEL INVERTER}

For spectral analysis, reference command to the hybrid inverter can be represented as

$$
V_{\mathrm{ref}}=M \cos \omega t
$$

where $M$ is the modulation depth which varies between $0 \leq$ $M \leq 1$ and $\omega$ is the angular frequency of the reference signal. Therefore, the IGCT inverter output and the IGBT inverter leg command are given by [10]

$$
V_{\mathrm{IGCT}}=\Sigma \frac{8}{3 n \pi} \sin \left\{n \cos ^{-1} \frac{1}{3 M}\right\} \cos n \omega t(\text { for odd } n)
$$

$V_{\text {IGBT (command) }}=M \cos \omega t-\Sigma \frac{8}{3 n \pi} \sin \left\{n \cos ^{-1} \frac{1}{3 M}\right\}$ $\cdot \cos n \omega t($ for odd $n)$. 


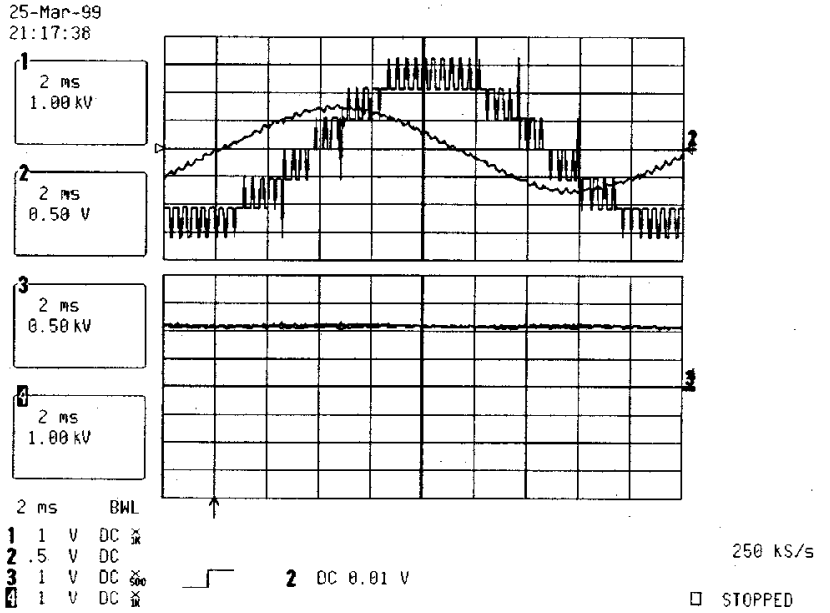

Fig. 7. Experimental load and dc-bus voltage waveforms, $M=0.83$ p.u. and $f_{c}=1440 \mathrm{~Hz}$. Trace 1: Output voltage $1000 \mathrm{~V} /$ div. Trace 2: Output current 5 A/div. Trace 3: IGBT dc bus $500 \mathrm{~V} /$ div. Trace 4: IGCT dc bus $1000 \mathrm{~V} /$ div.

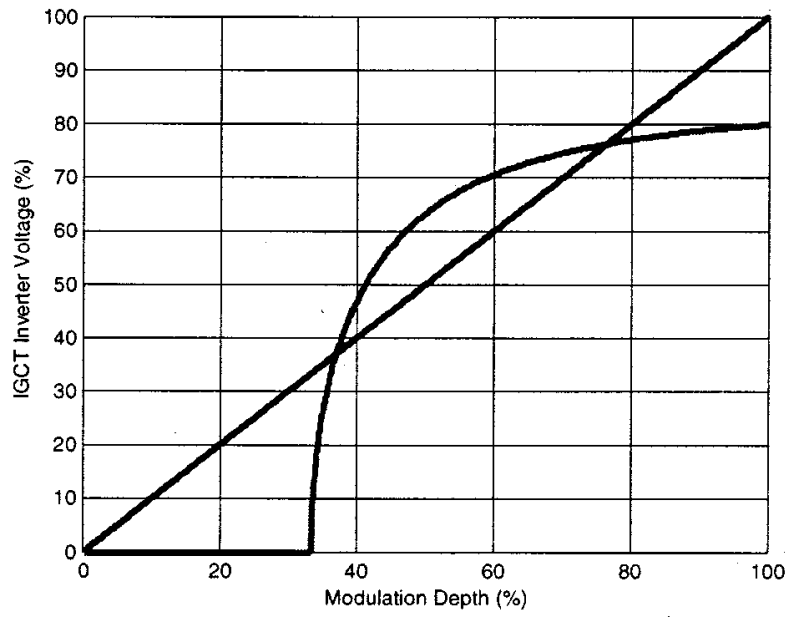

Fig. 8. IGCT inverter fundamental voltage as a function of modulation depth

Now, spectrum of a naturally sampled sine-triangle PWM single-phase voltage-source inverter (VSI) with a leg command $A \cos \omega_{o} t$ and carrier frequency $\omega_{c}$ is given in [9] as follows:

$$
\begin{aligned}
V_{\mathrm{VSI}}= & A \cos \omega_{o} t+\frac{4}{\pi} \Sigma \Sigma \frac{1}{2 m} J_{2 n-1} A m \pi \\
& \cdot \cos \left\{2 m \omega_{c} t+(2 n-1) \omega_{o} t\right\} \\
& (\text { summations from } m=1 \text { to } \infty \\
& \quad \text { and } n=-\infty \text { to }+\infty) .
\end{aligned}
$$

One can substitute (3) in (4) and obtain a complete spectrum for the PWM IGBT inverter. This, when added to the spectrum of the IGCT inverter (2), gives a complete spectrum of the hybrid inverter [10]. Particularly, behavior of the individual inverters at fundamental frequency is interesting. The IGCT inverter output under hybrid modulation is plotted against the modulation depth in Fig. 8. It is overlaid on a unity slope line which specifies the commanded fundamental voltage. It may be observed that the IGCT inverter synthesizes more voltage than necessary between the modulation depths around $37 \%$ and $78 \%$.

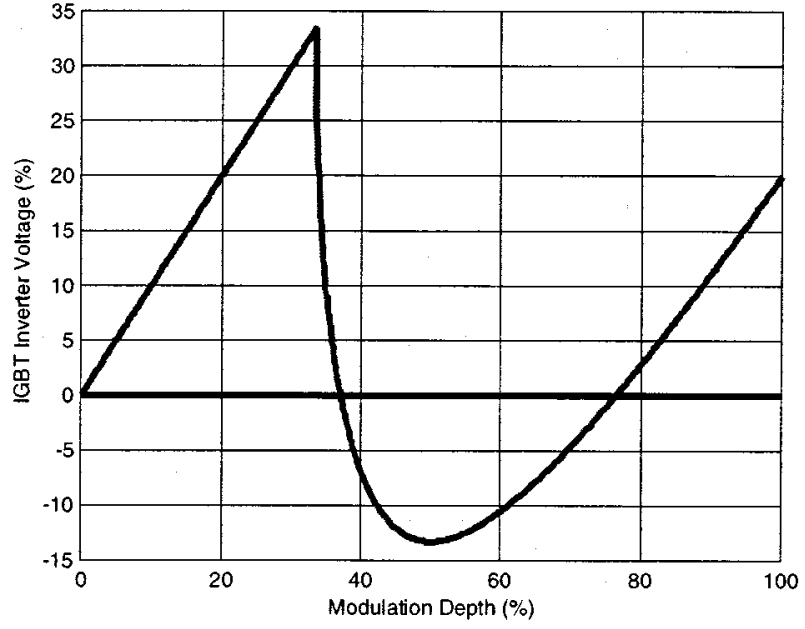

Fig. 9. IGBT inverter fundamental voltage as a function of modulation depth.

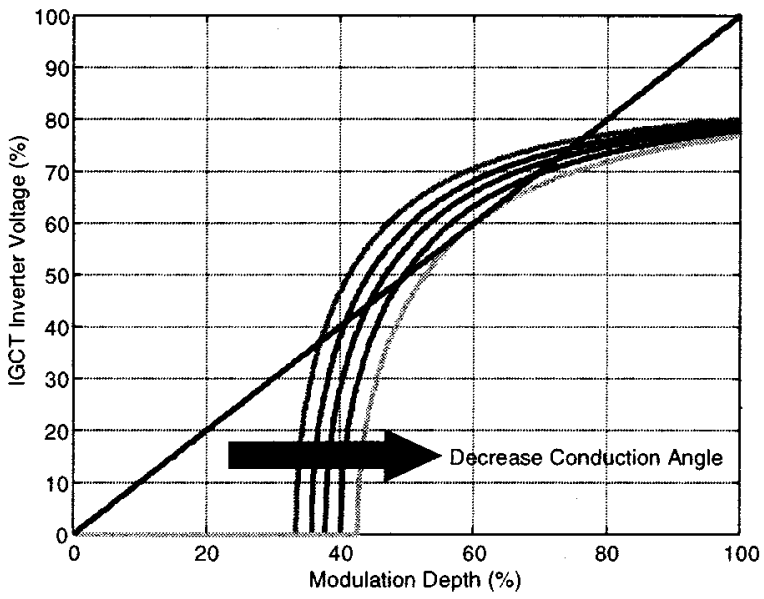

Fig. 10. Conduction angle control of the IGCT inverter.

Hence, it is necessary for the IGBT inverter to cancel this excessive voltage, as illustrated in Fig. 9. As may be seen from the fundamental voltage synthesized by the IGBT inverter, this inverter synthesizes negative voltage in this region of modulation depths. In terms of real power flow, which is represented by the current component that is in phase with the fundamental voltage, it appears that the IGCT inverter feeds the power into the IGBT inverter in this zone. A simple solution for this problem is to control the conduction angle of the IGCT inverter such that the fundamental voltage generated by this inverter is always less than the total commanded voltage [10]. This is depicted in Fig. 10. A more sophisticated version of the solution is to solve this problem with a regenerative IGBT rectifier, as will be described next.

\section{PRINCIPLE OF THE Hybrid Multilevel Rectifier}

It is well known that the conventional six-pulse rectifier bridges suffer from a strong harmonic interaction with the utility [11]. Therefore, present-day $\mathrm{H}$-bridge multilevel inverters employed for feeding medium-voltage loads control the utility harmonic impact by means of specially designed transformers which provide an 18-pulse (see Fig. 1) or a 30-pulse 


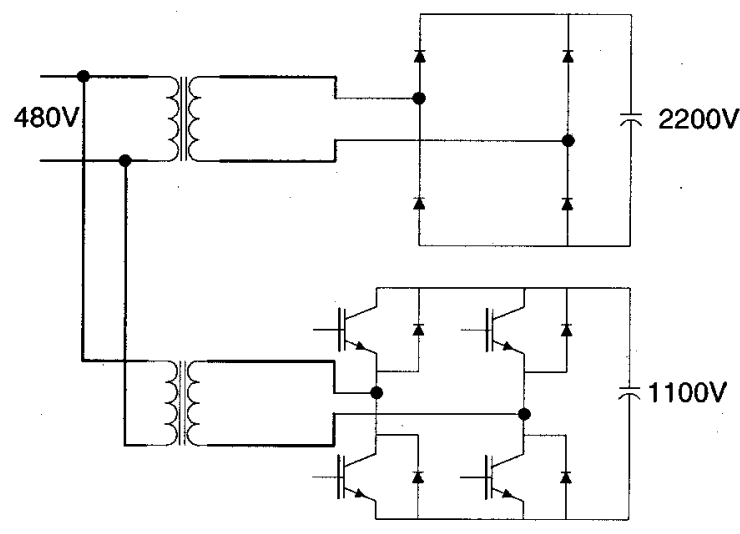

Fig. 11. Simplified schematic of one leg of the hybrid multilevel rectifier (utility and transformer leakage inductance not shown).

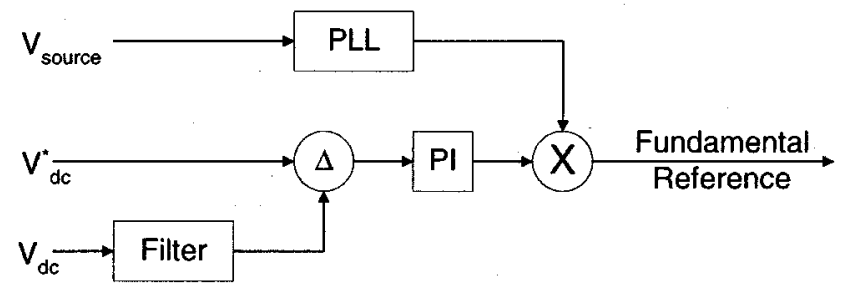

Fig. 12. Simplified schematic of fundamental current reference generation.

input current [4]. Hence, to simplify transformer design and interconnections combined with a low harmonic impact on the utility interface, it is proposed to use an active rectifier for the IGBT inverter along with a diode bridge front end for the IGCT inverter, as shown in Fig. 11. With this configuration, it is possible to use the IGBT rectifier as an active filter for the harmonics generated by the high-voltage passive rectifier, as well as a real power flow controller for the low-voltage converter, thereby regulating its dc-bus voltage irrespective of power interaction in the hybrid inverter.

The control action for the hybrid multilevel rectifier can be partitioned into two tasks: reference generation and current control.

\section{A. Reference Generation}

It may be noted that, unlike the conventional active rectifiers (where the current reference is purely fundamental [11]) or the conventional active filters (where the current reference is purely harmonic [12]), current reference in this particular case is comprised of two components, fundamental and harmonic. The fundamental current reference is obtained from the dc-bus voltage controller, as shown in Fig. 12. As may be seen from this figure, this reference generation procedure is similar to that in a conventional active rectifier [11]. The dc link in the low voltage converter is sensed and filtered and then compared against a command $(1100 \mathrm{~V})$. The error is fed to a proportional-integral (PI) controller, which gives the magnitude of the current to be synthesized. This magnitude is multiplied with unit amplitude sinusoid that is phase locked with the source voltage. Thus, a reference fundamental current waveform is generated that is in phase with the utility voltage.

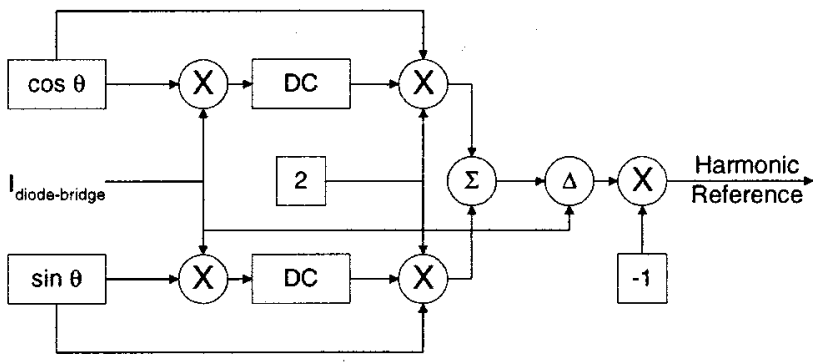

Fig. 13. Simplified schematic of harmonic current reference generation.

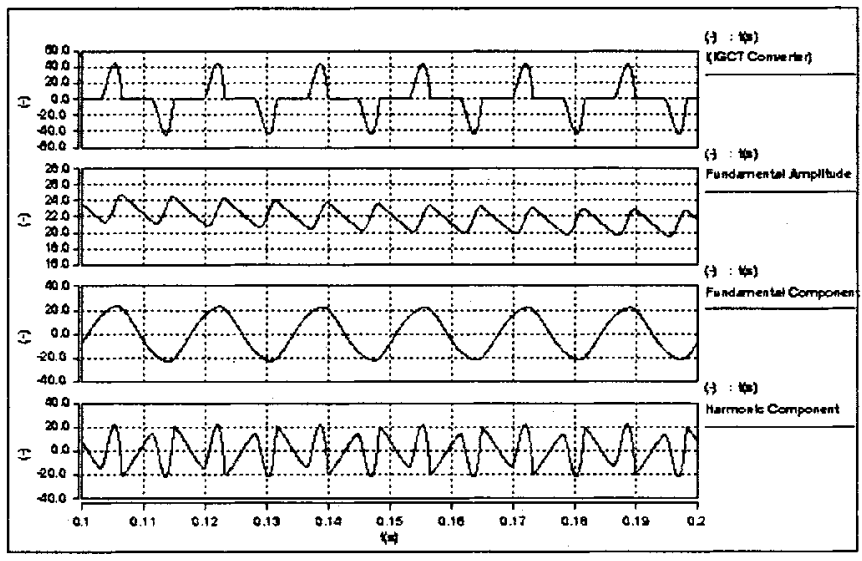

Fig. 14. Simulated waveforms for harmonic component extraction from current drawn by the diode bridge. Trace 1: Current drawn by the diode bridge. Trace 2: Amplitude of the fundamental component. Trace 3: Waveform of the fundamental component. Trace 4: Waveform of the harmonic component.

The harmonic current reference is extracted from the current drawn by the high-voltage power converter, as shown in Fig. 13. The harmonic extraction procedure is based on the fact that any sinusoidal waveform can be resolved in two orthogonal components. The fundamental component in the current drawn by the diode bridge can also be treated in the same manner. This current is sensed and is multiplied with an arbitrary orthogonal set of waveforms, in this case, unit amplitude sine and cosine waveforms. The components that are not in phase with these sine and cosine waves average out to null and can be easily separated, whereas the components that are in phase form square terms which have dc values of one-half the amplitude. Hence, these dc magnitudes are extracted and multiplied by two to give the projections of the fundamental component on the orthogonal axes. These projections when multiplied to the original set of orthogonal waveforms and added together give the fundamental component of the diode bridge input current. Now, one can obtain the harmonics in this current by subtracting the fundamental component from the original current. It may be noted that an alternative means to obtain the harmonic components is to employ a filter to remove the fundamental component. However, performance of such an approach is frequency dependent and, hence, not recommended [12]. The procedure described above to extract the harmonic component is time instantaneous and can be repeated for all three legs. A harmonic current reference is now generated simply by inverting this harmonic component. Thus, in effect, the IGBT rectifier also needs to draw equal and opposite harmonic current as drawn by the high-voltage diode rec- 


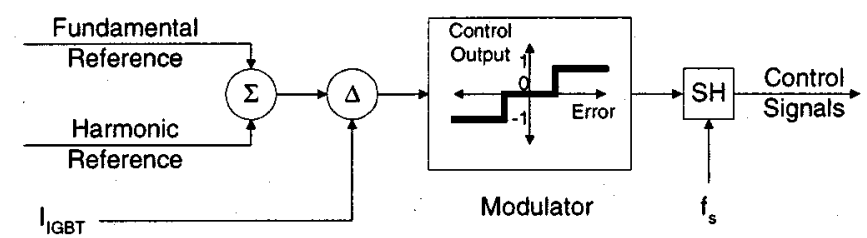

Fig. 15. Simplified schematic of multilevel current-regulated delta modulator.

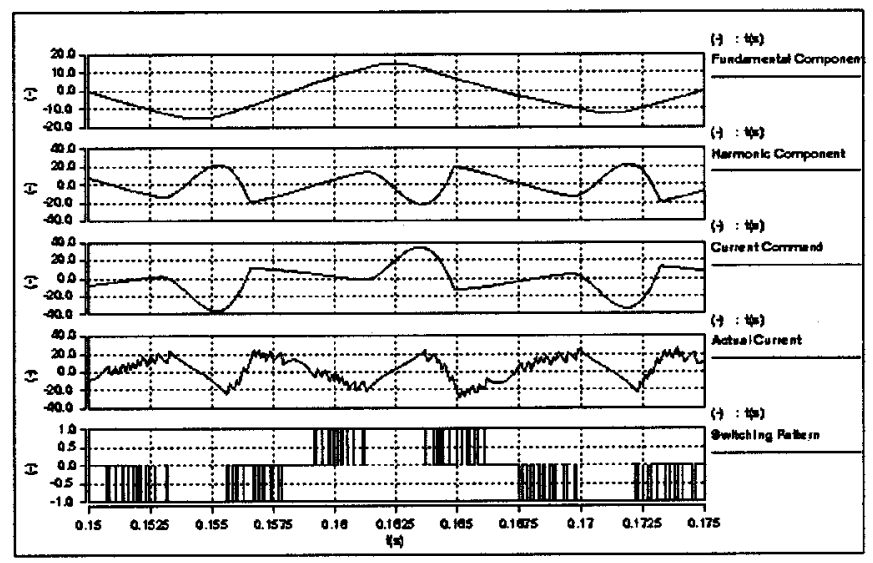

Fig. 16. Simulated waveforms for reference generation and current control, $V_{\mathrm{dc}(\mathrm{IGBT})}=1100 \mathrm{~V}$ and $f_{\mathcal{s}}=10 \mathrm{kHz}$. Trace 1: Fundamental current reference. Trace 2: Harmonic current reference. Trace 3: Reference current command to the IGBT rectifier. Trace 4: Actual current drawn by the IGBT rectifier. Trace 5: Control signals generated from the resultant error.

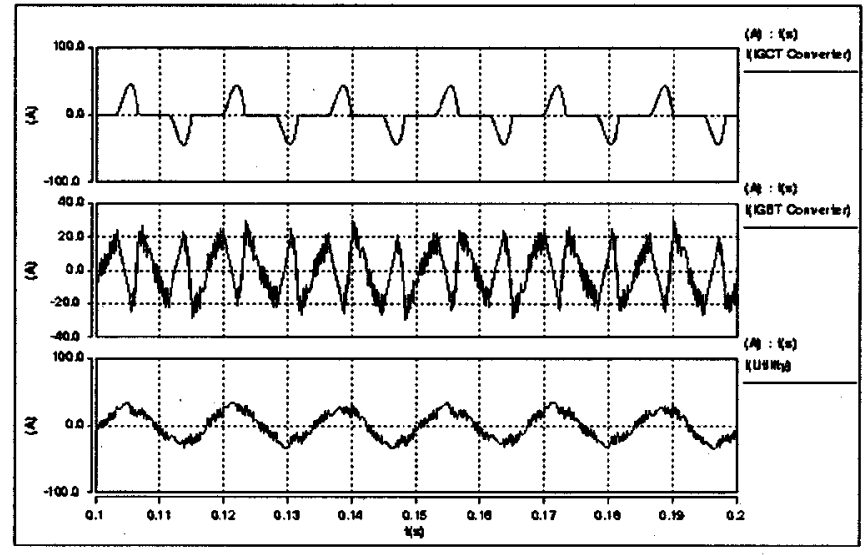

Fig. 17. Simulated waveforms for currents drawn by individual rectifiers and the resultant interaction with utility, $V_{\mathrm{dc}(\mathrm{IGBR})}=1100 \mathrm{~V}$ and $f_{s}=10 \mathrm{kHz}$. Trace 1: Current drawn by the diode bridge rectifier. Trace 2: Current drawn by the IGBT rectifier. Trace 3: Current drawn from the utility power supply.

tifier, thereby maintaining a clean interface at the utility. Simulated waveforms of harmonic extraction for one leg are shown in Fig. 14. It is easily possible to extend this result to a three-phase system.

\section{B. Current Control}

Since the current references are nonsinusoidal, a hysteresis current regulator is a popular choice for current control with sufficient dynamic capability. However, this type of regulator suffers from phase interaction and low-frequency current errors, in particular, for nonsinusoidal multiple-frequency tracking [12].

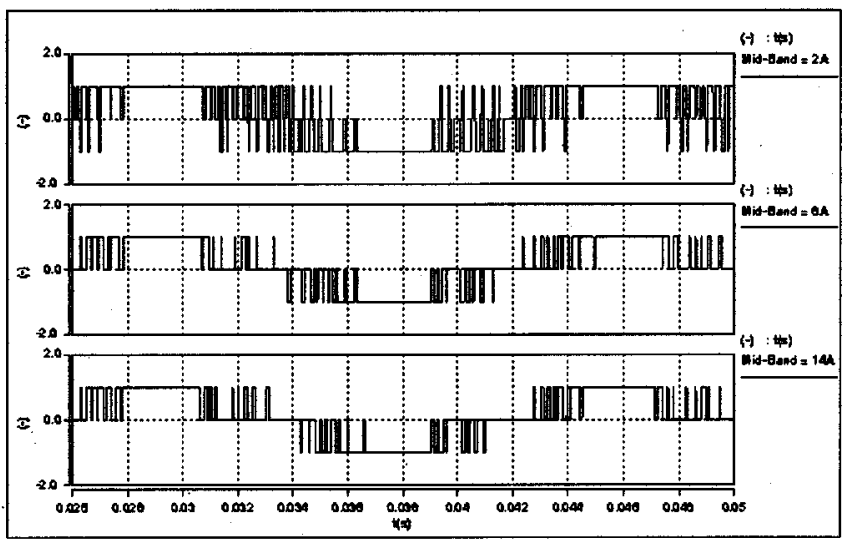

Fig. 18. Simulated waveforms for control signals at various widths of midband. Trace 1: Control signals for narrow error-band. Trace 2: Control signals for nominal error-band. Trace 3: Control signals for wide error band.

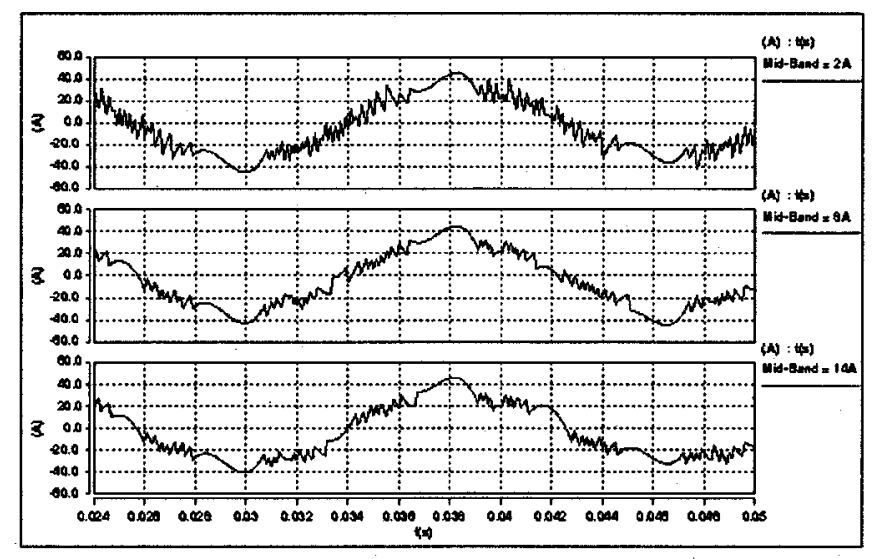

Fig. 19. Simulated waveforms for resultant utility currents at various widths of midband. Trace 1: Utility currents with narrow error band. Trace 2: Utility currents with nominal error band. Trace 3: Utility currents with wide error band.

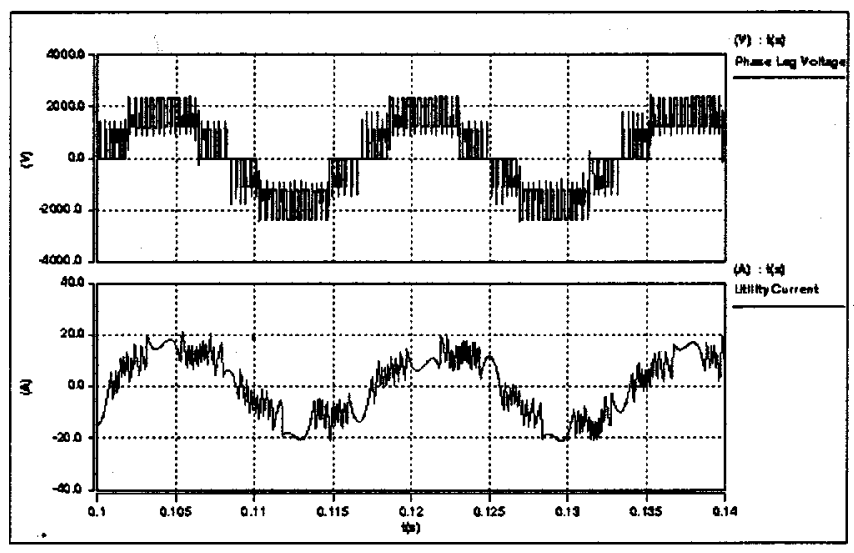

Fig. 20. Simulated waveforms for multilevel inverter phase leg voltage output and utility current at $M=0.5$ p.u.

Hence, the current control is accomplished by a three-level delta modulator based on the family of delta modulators popular for their dynamic capability [13]. A multilevel delta modulator is realized by replacing the two-level comparator in the conventional delta modulator by a tristate comparator with an intermediate error band [14]. A simplified schematic of a multilevel 


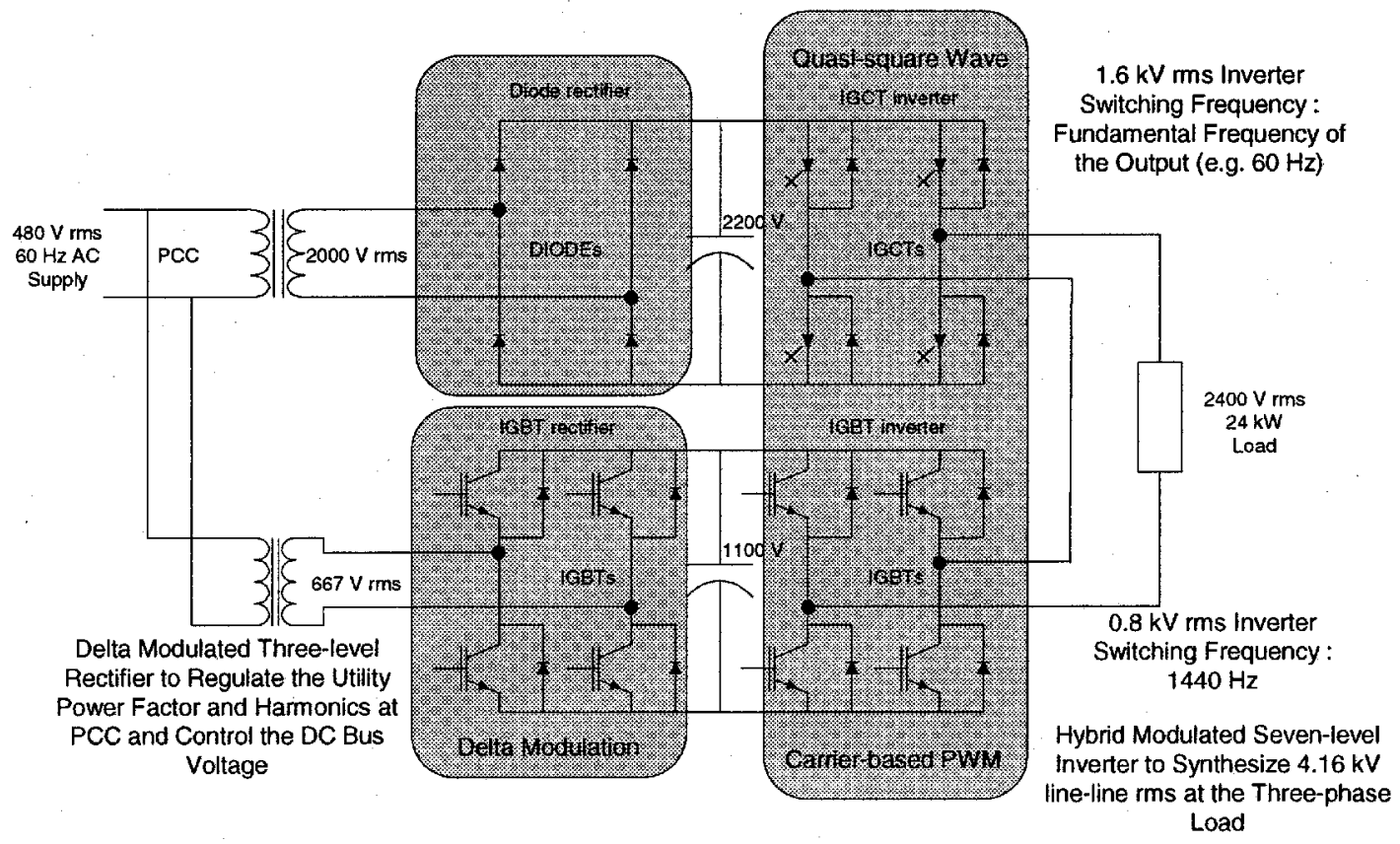

Fig. 21. Illustrated power circuit schematic of one phase of the hybrid multilevel power conversion system.

delta modulator is shown in Fig. 15. The output of the modulator may take values $+1,0$, or -1 depending on the magnitude of error signal which is the difference between the reference and the actual current. This output is sampled at a constant frequency $\left(f_{s}\right)$ and fed to the rectifier switches. The reference current (sum of fundamental and harmonic current references) and the control signals are shown in Fig. 16.

\section{Simulation Results of THE HybRid MULTILEVEL RECTIFIER}

The hybrid multilevel rectifier is controlled with a multilevel current-regulated delta modulator sampled at $10 \mathrm{kHz}$. It is possible to reduce the sampling frequency further by employing programmed PWM techniques, and is currently under investigation. With the hybrid topology and control strategy, the dc-link voltage in the IGBT converter and input harmonic currents in the IGCT converter are regulated. This is demonstrated in the current waveforms shown in Fig. 17. It may be observed that, although the diode bridge draws currents with high harmonic content, the IGBT rectifier compensates them with equal and opposite currents. This produces a near-sinusoidal current at the utility interface, as depicted in Fig. 17. The dc link in the IGBT converter is also regulated within $5 \%$ and has been shown in Fig. 5.

In addition, it may also be noted from Fig. 15 that the sampling frequency $\left(f_{s}\right)$ in the sample/hold and the width of the error band in the tristate comparator determine the spectral properties of the resulting waveforms. Intuitively, it seems that the current regulation improves as the quantization error band approaches zero. However, decreasing the error band also reduces the occurrence of zero states, which effectively increases the ripple current. Conversely, widening the error band leads to loss of current control, thus constraining its upper limit. These effects are shown in Figs. 18 and 19. It is possible to optimize the width of the error band depending on the harmonic distortion in the utility current; however, this optimization is application specific and is not treated here.

Finally, the utility current and multilevel inverter output at $M=0.5$ p.u. is shown in Fig. 21. This operating point falls under the IGBT regeneration zone (Fig. 9). As explained in the spectral analysis, the IGCT inverter feeds the power to the IGBT inverter in this operating region. However, it is clear from Fig. 21 that the system operation is stable and well behaved with the proposed control strategy in this zone.

\section{CONCLUSIONS}

A hybrid approach in multilevel power conversion has been presented. An illustrated power circuit schematic is shown in Fig. 20. It seems that the conventional H-bridge multilevel inverter is the only topology that has received a reasonable consensus along with the neutral-point-clamped inverter [15] in the high-power community. However, the industrial implementation of such a system suffers from a principal drawback of the tradeoff between harmonic interaction with the utility and complicated transformer connections. A primary advantage of the hybrid multilevel inverter is that it generates a larger number of levels with a given number of power devices or H-bridge modules. This reduces the output current distortion, thereby improving the power conversion capability at the load. This fact has been verified with simulation as well as experimental results in this paper. Secondly, it employs a synergistic approach in utilizing the devices, such as to obtain the advantages of both the technologies: latching devices for their high-voltage blocking capability and nonlatching devices for their fast-switching capability. Hence, although the overall device kilovoltampere rating is the same as that of a conventional H-bridge multilevel inverter, one can obtain a significant cost reduction with appropriate selection of devices. Finally, by employing a hybrid rec- 
tifier, it is possible to relieve the utility supply from harmonic interaction to a large extent. As may be seen from the simulation results presented in this paper, near-sinusoidal currents can be drawn from the utility by using only one active rectifier per phase. This eliminates the need of multiple winding transformers with complicated interconnections to produce $18 / 30$ pulse current waveforms.

These attributes offer an incentive to pose the HMPC system (see Fig. 20) as a competitive alternative to the conventional $\mathrm{H}$-bridge and even to the established neutral-point-clamped technology in medium-voltage applications.

\section{REFERENCES}

[1] J. S. Lai and F. Z. Peng, "Multilevel converters-A new breed of power converters," in Conf. Rec. IEEE-IAS Annu. Meeting, 1995, pp. $2348-2356$.

[2] B. S. Suh, G. Sinha, M. D. Manjrekar, and T. A. Lipo, "Multilevel power conversion-An overview of topologies and modulation strategies," in Proc. OPTIM'98, 1998, pp. AD-11-AD-24.

[3] M. Marchesoni, M. Mazzucchelli, and S. Tenconi, "A non-conventional power converter for plasma stabilization," in Proc. IEEE PESC'88, 1988, pp. 122-129.

[4] P. W. Hammond, "Medium voltage PWM drive and method," U. S. Patent 5 625 545, 1997.

[5] B. J. Baliga, Power Semiconductor Devices. Boston, MA: PWS, 1996.

[6] P. Steimer, H. E. Gruning, J. Werninger, E. Carroll, S. Klaka, and S. Linder, "IGCT-A new emerging technology for high power low cost inverters," in Conf. Rec. IEEE-IAS Annu. Meeting, 1997, pp. 1592-1599.

[7] M. D. Manjrekar and T. A. Lipo, "A generalized structure of multilevel power converter," in Proc. IEEE PEDES'98, 1998, pp. 62-67.

[8] - "A hybrid multilevel inverter topology for drive applications," in Proc. IEEE APEC'98, 1998, pp. 523-529.

[9] D. M. Divan and T. A. Lipo, "Class Notes for ECE 712-Solid State Power Conversion Course," Univ. Wisconsin, Madison, Fall 1995.

[10] R. Lund, M. D. Manjrekar, P. Steimer, and T. A. Lipo, "Control strategies for a hybrid seven-level inverter," in Proc. EPE'99, 1999, CD-ROM.

[11] N. Mohan, T. Undeland, and W. Robbins, Power Electronics. New York: Wiley, 1995.

[12] S. Bhattacharya, T. M. Frank, D. M. Divan, and B. Banerjee, "Parallel active filter system implementation and design issues for utility interface of adjustable speed drive systems," in Conf. Rec. IEEE-IAS Annu. Meeting, 1996, pp. 1032-1039.

[13] M. Kheraluwala and D. M. Divan, "Delta modulation strategies for resonant DC link inverters," in Proc. IEEE PESC'87, 1987, pp. 271-278.

[14] M. Manjrekar and G. Venkataramanan, "Advanced topologies and modulation strategies for multilevel inverters," in Proc. IEEE PESC'96, 1996, pp. 1013-1018.

[15] A. Nabae, I. Takahashi, and H. Akagi, "A new neutral point clamped PWM inverter," IEEE Trans. Ind. Applicat., vol. IA-17, pp. 518-523, Sept./Oct. 1981

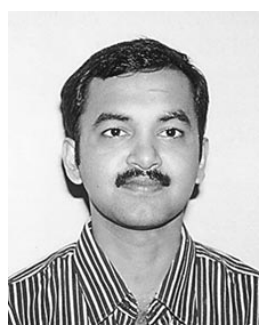

Madhav D. Manjrekar (S'96) was born in 1972. He received the B.E. degree from the Government College of Engineering, University of Pune, India, the M.Tech. degree from the Center for Electronic Design and Technology, Indian Institute of Science, India, and the M.S. degree from Montana State University, Bozeman, in 1993, 1995, and 1997, respectively. He is currently working toward the Ph.D. degree at the University of Wisconsin, Madison.

His research interests are modeling, design, and control of power conversion systems, utility applications of power electronics, adjustable-speed and torque drives, and nonlinear dynamics and controls.

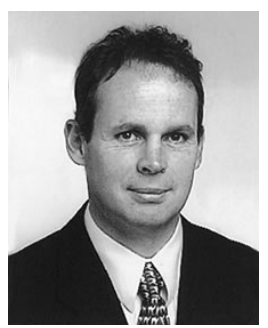

Peter K. Steimer (S'88-M'89) was born in Zurich, Switzerland, in 1956. He received the M.S. and Ph.D. degrees in electrical engineering from Swiss Federal Institute of Technology, Zurich, Switzerland, in 1981 and 1990 , respectively.

In 1981, he joined the BBC as a Research Engineer, where he worked in the field of control of drives and static var compensators. From 1991 until 1996, he was General Manager of the R\&D Department, ABB Industrie AG, with focus on the field of high-power electronics for drives, high-power VSC interties, static var compensators, and high-current rectifier and excitation systems. From 1994 to 1997, he was responsible within ABB for the development of the new IGCT technology. Since 1996, he has been acting as Manager of Technology and Innovation at ABB Industrie AG, Turgi, Switzerland. In 1998-1999, he was on a nine-month sabbatical leave at the University of Wisconsin, Madison.

Dr. Steimer is a member of the International Steering Committee of the European Power Electronics and Drives Association (EPE).

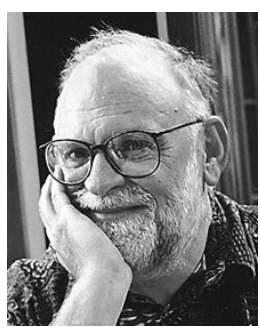

Thomas A. Lipo (M'64-SM'71-F'87) is a native of Milwaukee, WI. He received the B.E.E. and M.S.E.E. degrees from Marquette University, Milwaukee, WI, in 1962 and 1964, respectively, and the Ph.D. degree in electrical engineering from the University of Wisconsin, Madison, in 1968.

From 1969 to 1979, he was an Electrical Engineer in the Power Electronics Laboratory of Corporate Research and Development, General Electric Company, Schenectady, NY. He became Professor of Electrical Engineering at Purdue University, West Lafayette, IN, in 1979 and, in 1981, he joined the University of Wisconsin, Madison, in the same capacity. He is presently the W.W. Grainger Professor for Power Electronics and Electrical Machines, Co-Director of the Wisconsin Electric Machines and Power Electronics Consortium, and Director of the Wisconsin Power Electronics Research Center. 